\title{
COMPUTER CALCULATION OF PROBABILITY FOR BINARY COLLISIONS OF ELECTRONS WITH IONS AND MOLECULES
}

\author{
Yu.M. Marchuk, Yu.S. Kulyk, V.E. Moiseenko \\ National Science Center “Kharkov Institute of Physics and Technology”, Kharkiv, Ukraine
}

Computer calculation of rate coefficient for binary collision $\left\langle\sigma_{i} v\right\rangle$ as a function of temperature is presented, and the Maxwell electron velocity distribution function is chosen. The finite elements of the fifth order made it possible to significantly speed up the process of calculation $\left\langle\sigma_{i} v\right\rangle$. The result of the approximation is a smooth function and the values of this function, its first and second derivatives, have no jumps at the mesh nodes and the accuracy of calculation is within the limits of statistical errors for the source data. These advantages and the results will be used in future tasks.

PACS: 29.17.+w; 41.75.Lx

\section{INTRODUCTION}

In the non-equilibrium plasma, elastic and inelastic collisions determine the rates of many collision processes. Collisions of electrons with heavy particles (ion or with atom) are of the certain interest for plasma production and sustain. If you consider the case of elastic collisions, scattering is not accompanied by an appreciable loss of energy; in the case of inelastic interactions, the energy losses are higher.

The probability of electron scattering through a certain angle $\vartheta$ is determined by the value of the interaction potential of the scattering particle with the incident electron. It is proportional to the differential scattering cross section $d \sigma(v)=(d \sigma / d \Omega) d \Omega$ and the angular dependence of the scattering cross section $(d \sigma / d \Omega)$ can take as a simple form, which simplifies calculations and can be quite complex. Total rate coefficient for collisions with the relative velocity $v$ is defined as $\sigma_{i}(v)=\int(d \sigma / d \Omega) d \Omega$.

The frequency of collisions for monoenergetic electrons is determined by the expression $v_{e}(v)=v \sigma_{i}(v) n$ where $n$ is the density of particles which electron collides.

\section{FINITE ELEMENT APPROXIMATION}

Many problems in applied mathematics are reduced to solving different equations of various types (linear and non-linear). One of the powerful numerical methods is the finite element method, which is a universal tool for solving problems of mathematical physics.

The finite element method is based on the fact that any arbitrary and continuous function $\varphi(x)$ in the computational domain, for example, the temperature, can be approximated by a set of piecewise continuous functions defined on a finite number of subdomains (finite elements) [1].

The region of integration is divided into elements in such a way that on each of them the unknown function could be approximated, for example, by polynomials. Inside each element, an unknown function is represented by a linear combination of basis functions, unknown coefficients, while the values of the function are at the nodal points of the approximation. As coordinate functions, functions are taken that are identically zero everywhere, except for one finite element, inside which they coincide with the basis functions. Thus, the problem of approximating a function is reduced to a system of linear algebraic equations, the number of equations of which coincides with the number of nodal points. These elements have common anchor points and together they approximate the shape of the region.

The essence of the problem is that we need to approximate the known experimental data for electron impact ionization average cross section. This method meets our requirements, since excessive accuracy is not needed and the time spent on the calculation is rather small. Also, the advantages of the method are that the first and second derivatives at the mesh nodes are matching. For this reason, this method is suitable for calculations and can be used in work [2].

\section{FORMULATION OF THE PROBLEM}

There are Lagrangian and Hermitian finite elements and each of them has its own advantages. The main disadvantage of Lagrangian finite elements is that they include additional points on the segment and derivatives at the main nodes are not matching. We use fifth degree polynomials to approximate a function for which the first and the second derivative are matching at the mesh nodes. This is essential advantage of Hermitian finite elements. In accordance with the above written we will be use the fifth-order Hermitian finite element approximation for the rate coefficient. A powerful tool for simulating processes in plasma is described in the work [3].

Using the general formula for the rate coefficient for probability of binary collisions:

$$
S v \equiv<\sigma_{i} v>=\int f_{e} \sigma_{i}(v) v d^{3} v,
$$

we assume that the velocity distribution function is the normalized Maxwellian:

$$
f_{e}=f_{e M}=\frac{1}{\pi^{3 / 2} v_{T e}^{2}} \exp \left(-\frac{v^{2}}{v_{T e}^{2}}\right),
$$

where $v$ is the velocity of electrons. Thermal velocity $v_{T e}=\sqrt{2 k T / m_{e}}$ depends on temperature, where $k$ is the Boltzmann constant, $T$ is the temperature of electrons, $m_{e}$ is the mass of the electrons. 
Next, we take the $\sigma$ values for the ionization crosssection of the hydrogen atom from review [4] and approximate with columns (piecewise constant elements) which defined on finite number of subdomains (Fig. 1).

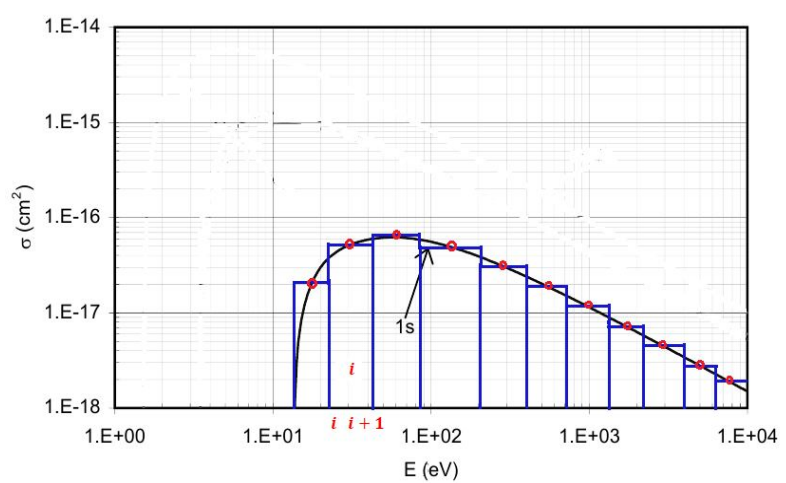

Fig. 1. Function approximation using piecewise constant elements for electron impact ionization cross-section [4]

The required function $S v$ depends on the electron temperature. Next, we introduce a temperature data grid with equidistant nodes $i$. We make the following change of variable: $u=v^{2} / v_{T e}^{2}$.

At each grid interval, we represent the $\sigma$ as a constant value and analytically calculate the integral. The number of such integrals is equal to the number of intervals; therefore, we can represent equation (1) as a sum by the number of nodal points $i$.

$$
S v=\sum_{i=1}^{N-1} A\left\{\left(1+u_{i}\right) \exp \left(-u_{i}\right)-\left(1+u_{i+1}\right) \exp \left(-u_{i+1}\right)\right\} \text {, }
$$

where $N$ is the number of points, $A=2 v_{T e} \sigma_{i} / \sqrt{\pi}$, $u_{i}$ and $u_{i+1}$ is the lower and upper integration.

It is also of interest to calculate the first and second derivatives of the function $S v$ with respect to temperature:

$$
\begin{gathered}
d(S v) / d T=\sum_{i=1}^{N-1} \frac{A}{T} \exp \left(-u_{i}\right)\left[2 u_{i}^{2}+u_{i}+1\right]- \\
-\frac{A}{T} \exp \left(-u_{i+1}\right)\left[2 u_{i+1}^{2}+u_{i+1}+1\right] \\
d^{2}(S v) / d T^{2}=\sum_{i=1}^{N-1} \frac{A}{T} \exp \left(-u_{i}\right)\left[\frac{2\left(u_{i}^{3}-2 u_{i}^{2}\right)}{T}-\frac{u_{i}+1}{2}\right]- \\
-\frac{A}{T} \exp \left(-u_{i+1}\right)\left[\frac{2\left(u_{i+1}^{3}-2 u_{i+1}^{2}\right)}{T}-\frac{u_{i+1}+1}{2}\right]
\end{gathered}
$$

A program has been written that makes it possible using equations (3) - (5) to calculate the $S v$ for any value of temperature of electrons. $S v$ is the continuous in temperature and all derivatives exist and this is the advantage of this program. But the main disadvantage is that the program calculates slowly, since (3) - (5) contains summation over the number of intervals and it takes time.

The task is to simplify the $S v$ calculation, we will approximate the results using Hermitian finite elements with a polynomial of the fifth degree. Next, we introduce a new grid of temperature data.
$M$ is the number of intervals, $k$ is the discrete variable which enumerates of mesh nodes and varies from 1 to $M$.

$$
\begin{gathered}
\left.S v\right|_{T_{k}<T<T_{k+1}}=\lambda_{1}(\xi) S v_{i}+\lambda_{2}(\xi)\left(\frac{d S v}{d T}\right)_{i}+\lambda_{3}(\xi)\left(\frac{d^{2} S v}{d T^{2}}\right)_{i}+ \\
+\lambda_{4}(\xi) S v_{i+1}+\lambda_{5}(\xi)\left(\frac{d S v}{d T}\right)_{i+1}+\lambda_{6}(\xi)\left(\frac{d^{2} S v}{d T^{2}}\right)_{i+1} . \text { (6) }
\end{gathered}
$$

Below are the finite elements for the fifth degree polynomial [5]:

$\lambda_{1}(\xi)=1-10 \xi^{3}+15 \xi^{4}-6 \xi^{5}$,

$\lambda_{2}(\xi)=\Delta_{k}\left(\xi-6 \xi^{3}+8 \xi^{4}-3 \xi^{5}\right)$,

$\lambda_{3}(\xi)=\frac{1}{2} \Delta_{k}^{2}\left(\xi^{2}-3\left(\xi^{3}-\xi^{4}\right)-\xi^{5}\right)$,

$\lambda_{4}(\xi)=1-10(1-\xi)^{3}+15(1-\xi)^{4}-6(1-\xi)^{5}$,

$\lambda_{5}(\xi)=-\Delta_{k}\left[(1-\xi)-6(1-\xi)^{3}+8(1-\xi)^{4}-3(1-\xi)^{5}\right]$,

$\lambda_{6}(\xi)=\frac{1}{2} \Delta_{k}^{2}\left[(1-\xi)^{2}-3\left((1-\xi)^{3}-(1-\xi)^{4}\right)-(1-\xi)^{5}\right]$,

where

$$
\Delta_{k}=T_{k+1}-T_{k}, \quad \xi=\frac{\left(T-T_{k}\right)}{\left(T_{k+1}-T_{k}\right)} .
$$

\section{NUMERICAL RESULTS OF MODELLING}

The next step is to write a Fortran program. In order to calculate $S v$ using formula (6) in Fortran, we need to know the constants, namely $S v_{i},(d S v / d T)_{i}$, and $\left(d^{2}(S v) / d T^{2}\right)_{i}$ which are calculated at each nodal point. Since these constants are required, at the preparatory stage, our program launches a program that calculates the equations (3) - (5) and fills with these values at the nodes of its own mesh. When this stage is passed our program is ready to work.

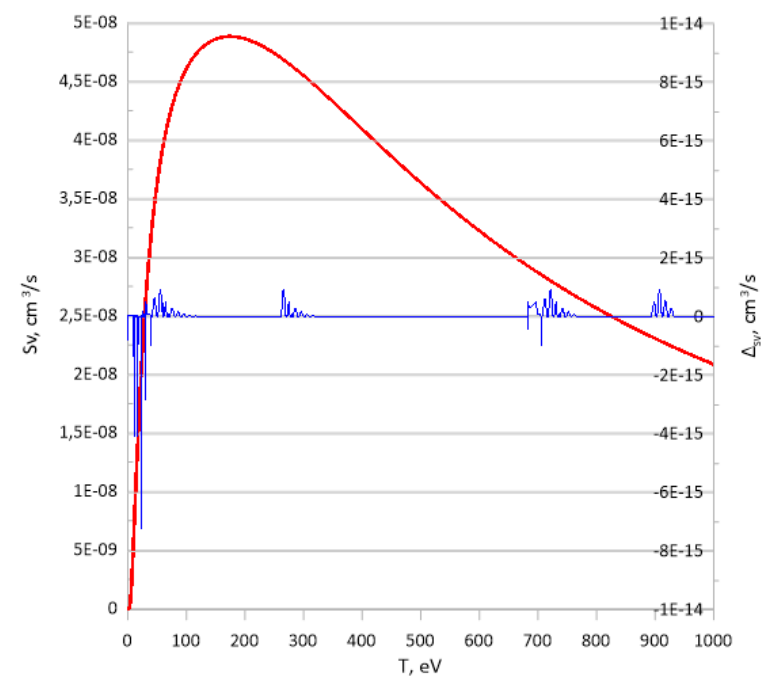

Fig. 2. Sv values which are calculated by direct and approximation method at each temperature value

$\Delta_{S v}$ is the deviation values of the direct method from the approximation method

For numerical experiments, we chose a temperature range from 0 to $1000 \mathrm{eV}$ and chose 100000 temperature 
values in which we will calculate $S v$. Next, we made the calculation using the new program (we will call the approximation method) and using the old program (direct method) and compared the time of their calculation, the results are shown below:

$t_{\text {appr }}=0.109201 \mathrm{~s}$ is the approximation method,

$t_{\text {cycle }}=3.08882 \mathrm{~s}$ is the direct method.

Numerical simulation results are presented in Fig. 2. The figure shows that the result for one function calculated in two different method is the same.

\section{CONCLUSIONS}

At the first stage, a method was developed for calculating $S v$ for electronic collisions using tabular values of $\sigma$. The calculation of $S v$ as a function of temperature is proposed. A distinctive feature is that $S v$ function is quickly calculated, and also the result of the approximation of $S v$ is a smooth function and the values of this function have no jumps. The application of polynomials in finite elements of the fifth order made it possible to speed up the process of calculating Sv by about 30 times $\frac{t_{\text {cycle }}}{t_{\text {appr }}}=28.27$. These advantages will be used in future tasks.

\section{REFERENCES}

1. O. Zenkevich, K. Morgan. Finite elements and approximation. New York: "John Wiley \& Sons", 1983, 328 p.

2. Y.S. Kulyk, V.E. Moiseenko, T. Wauters, A.I. Lyssoivan. Modelling of radio-frequency wall conditioning in short pulses in a stellarator. Problems of Atomic Science and Technology. Series “Plasma Physics". 2021, № 1(131), p. 9-14.

3. J.D. Lore et al. Implementation of the 3D edge plasma code EMC3-EIRENE on NSTX // Nuclear Fusion. 2012, v. 52, № 5, p. 054012.

4. R.K. Janev, D. Reiter, U. Samm. Collision processes in low-temperature hydrogen plasmas. Jülich: Forschungszentrum, Zentralbibliothek, 2003, t. 4105 .

5. C.C. Ike, E.U. Ikwueze. Fifth degree Hermittian polynomial shape functions for the finite element analysis of clamped simply supported EulerBernoulli beam //American Journal of Engineering Research (AJER). 2018, v. 7, № 4, p. 97-105.

Article received 04.06.2021

\section{КОМПЬЮТЕРНЫЙ РАСЧЕТ ВЕРОЯТНОСТИ ПАРНЫХ СТОЛКНОВЕНИЙ ЭЛЕКТРОНОВ С ИОНАМИ И МОЛЕКУЛАМИ}

\section{Ю.М. Марчук, Ю.С. Кулик, В.Е. Моисеенко}

Предложен компьютерный расчет вероятности парных столкновений $<\sigma_{i} v>$ как функции от температуры. Выбрана максвелловская функция распределения электронов по скоростям. Конечные элементы пятого порядка позволили значительно ускорить процесс расчета $<\sigma_{i} v>$. Результатом аппроксимации является гладкая функция. Значения этой функции, ее первой и второй производных не имеют скачков в узлах сетки, а точность расчета находится в пределах статистических ошибок исходных данных. Эти преимущества и результаты будут использованы в будущих задачах.

\section{КОМП'ЮТЕРНИЙ РОЗРАХУНОК ЙМОВІРНОСТІ ПАРНИХ ЗІТКНЕНЬ ЕЛЕКТРОНІВ З ІОНАМИ ТА МОЛЕКУЛАМИ}

\section{Ю.М. Марчук, Ю.С. Кулик, В.С. Моісеєнко}

Запропоновано комп’ютерний розрахунок вірогідності парних зіткнень $<\sigma_{i} v>$ як функції від температури. Вибрана максвелівська функція розподілу електронів за швидкостями. Скінченні елементи п'ятого порядку дозволили значно прискорити процес обчислення $<\sigma_{i} v>$. Результатом апроксимації є гладка функція. Значення цієї функції, іiї першої та другої похідних не мають стрибків у вузлах сітки, а точність знаходиться в межах статистичних помилок вхідних даних. Переваги даного методу будуть використані в майбутніх задачах. 